Article

\title{
Dielectric Properties of Zinc Sulfide Concentrate during the Roasting at Microwave Frequencies
}

\author{
Guangjun He 1,2,3,4,5, Shiwei Li $2,3,4,5$, Kun Yang 2,3,4,5, Jian Liu 2,3,4,5, Peng Liu 2,3,4,5, \\ Libo Zhang $2,3,4,5, *$ and Jinhui Peng $2,3,4,5, *$ \\ 1 Faculty of Science, Kunming University of Science and Technology, Kunming 650500, China; hegj9@126.com \\ 2 State Key Laboratory of Complex Nonferrous Metal Resources Clean Utilization, \\ Kunming University of Science and Technology, Kunming 650039, China; lswei11@163.com (S.L.); \\ turepsyche@gmail.com (K.Y.); powerliu@kmust.edu.cn (J.L.); 77penghp@gmail.com (P.L.) \\ 3 Yunnan Provincial Key Laboratory of Intensification Metallurgy, Kunming 650093, China \\ 4 National Local Joint Laboratory of Engineering Application of Microwave Energy and Equipment \\ Technology, Kunming 650093, China \\ 5 Faculty of Metallurgical and Energy Engineering, Kunming University of Science and Technology, \\ Kunming 650093, China \\ * Correspondence: lbzhang@kmust.edu.cn (L.Z.); jhpeng@kmust.edu.cn (J.P.)
}

Academic Editor: William Skinner

Received: 6 December 2016; Accepted: 4 February 2017; Published: 21 February 2017

\begin{abstract}
Microwave technology has a potential application in the extraction of zinc from sulphide ores, knowledge of the dielectric properties of these ores plays a major role in the microwave design and simulation for any process. The dielectric properties of zinc sulfide concentrate for two different apparent densities- 1.54 and $1.63 \mathrm{~g} / \mathrm{cm}^{3}$ — have been measured by using the resonance cavity perturbation technique at 915 and $2450 \mathrm{MHz}$ during the roasting process for the temperature ranging from room temperature to $850{ }^{\circ} \mathrm{C}$. The variations of dielectric constant, the dielectric loss factor, the dielectric loss tangent and the penetration depth with the temperature, frequency and apparent density have been investigated numerically. The results indicate that the dielectric constant increases as the temperature increases and temperature has a pivotal effect on the dielectric constant, while the dielectric loss factor has a complicated change and all of the temperature, frequency and apparent density have a significant impact to dielectric loss factor. Zinc sulfide concentrate is high loss material from 450 to $800{ }^{\circ} \mathrm{C}$ on the basis of theoretical analyses of dielectric loss tangent and penetration depth, its ability of absorbing microwave energy would be enhanced by increasing the apparent density as well. The experimental results also have proved that zinc sulfide concentrate is easy to be heated by microwave energy from 450 to $800^{\circ} \mathrm{C}$. In addition, the experimental date of dielectric constant and loss factor can be fitted perfectly by Boltzmann model and Gauss model, respectively.
\end{abstract}

Keywords: dielectric properties; microwave; zinc sulfide concentrate

\section{Introduction}

Zinc is the third most commonly used nonferrous metal and has a wide range of applications in the civilian and military fields. Zinc is mainly extracted from sulphide ores, oxide concentrates, silicates and zincous wastes. The extraction of zinc from sulphide minerals is carried out by two approaches: pyrometallurgical and hydrometallurgical processing, which is also known as the roast-leach-electrolysis combined process [1]. Now about $80 \%$ primary production of zinc is obtained from this combined process, although pyrometallurgy suffers from high energy consumption and $\mathrm{SO}_{2}$ emission and hydrometallurgy suffers from lengthy processing times and lower recoveries. So much attention has been paid to develop the processes which are less costly, more environmentally friendly and economically acceptable, for instance, using the microwave as an energy source [2]. 
The microwave energy has several advantages as compared to the traditional heating methods $[3,4]$. The dielectric properties are the key parameters for microwave heating because they determine how the microwave energy is absorbed, transmitted, reflected, or concentrated inside a material. The dielectric properties can be defined as the complex form [3]:

$$
\varepsilon_{\mathrm{r}}=\varepsilon_{\mathrm{r}}^{\prime}-j \varepsilon_{\mathrm{r}}^{\prime \prime}
$$

where $j$ is imaginary unit, $j^{2}=-1$, the relative dielectric constant $\left(\varepsilon_{\mathrm{r}}^{\prime}\right)$ measures how much energy transferred from an external electric field is stored in a material, whereas the relative dielectric loss factor $\left(\varepsilon_{\mathrm{r}}^{\prime \prime}\right)$ measures how lossy a material is to an external electric field. $\varepsilon_{\mathrm{r}}^{\prime}$ and $\varepsilon_{\mathrm{r}}^{\prime \prime}$ are crucial parameters to the microwave absorption in materials and efficiency of microwave processing $[5,6]$, they are effected by composition, temperature, microwave frequency, etc.

The ability of a special material converting microwave energy into heat at a given frequency and temperature is determined by the loss tangent $(\tan \delta)$. The dielectric loss tangent is expressed as $\tan \delta=\varepsilon_{\mathrm{r}}^{\prime \prime} / \varepsilon_{\mathrm{r}}^{\prime}$. In general a material with high $\tan \delta$ value at some microwave frequency is required for good absorption and efficient heating. Metaxas et al. categorizes materials based on the $\tan \delta$, low loss materials are those with $\tan \delta<3 \times 10^{-4}$, medium loss materials are those with $3 \times 10^{-4} \leq \tan \delta<$ $3 \times 10^{-2}$, and high loss materials with $\tan \delta \geq 3 \times 10^{-2}$ [7].

The power penetration depth $\left(D_{\mathrm{p}}\right)$ is defined as the distance at which power density of incident wave is reduced to 1/e of its value at surface of the material [8]. It is the measure of how deep a microwave radiation can penetrate into a material and it is calculated as follows:

$$
D \mathrm{p}=\frac{c}{2 \pi f \sqrt{2 \varepsilon_{\mathrm{r}}^{\prime}\left[\sqrt{1+\left(\frac{\varepsilon_{\mathrm{r}}^{\prime \prime}}{\varepsilon_{\mathrm{r}}^{\prime}}\right)^{2}}-1\right]}}
$$

where $c$ is the speed of light in free space $\left(3 \times 10^{8} \mathrm{~m} / \mathrm{s}\right)$, and $f$ is the micorowave frequency $(\mathrm{Hz})$.

The dielectric properties of zinc sulfide concentrate has rarely been reported up to now, especially for high temperature [2], although there are a considerable number of studies on the dielectric properties of materials and their evolution with temperature and frequency [6,9]. At present, a novel combination of phase transformation by using microwave roasting and leaching, can improve zinc extraction with high energy efficiency and hardly any $\mathrm{SO}_{2}$ emissions $[10,11]$. However, the kind and mass fraction of addition is dominantly based on experience analogy under the condition of no dielectric properties of zinc sulfide concentrate. Hence, it is important to know how the dielectric properties of zinc sulfide concentrate change with the temperature, microwave frequency, and apparent density.

The object of this work is to study the dielectric properties of zinc sulfide concentrate as affected by temperature (from room temperature to $850^{\circ} \mathrm{C}$ ), microwave frequency $(915$ and $2450 \mathrm{MHz}$ ) and apparent density in view of continuous thermal processing. Theoretical analyses have been also been conducted by calculating the loss tangent and penetration depth, The experiment value of dielectric constant and loss factor are fitted perfectly by Boltzmann model and Gauss model, respectively. It is hope that the data of dielectric properties in this paper can provide useful guidelines in designing and simulating microwave heating system of zinc sulfide concentrate.

\section{Experimental}

\subsection{Material and Preparation}

In the present study the zinc sulfide concentrate was obtained from Huize County of Yunnan province in China. The main chemical composition of the zinc sulfide concentrate is shown in Table 1, it can be seen that the zinc sulfide concentrate is mainly comprised by zinc, sulfide, ferrum and plumbum, zinc and sulfide make up about 84.14 percent mass fraction of the zinc sulfide concentrate. The zinc 
phase distribution in the zinc sulfide concentrate is presented in Table 2, it can be seen that zinc exists in the state of zinc sulfide, zinc carbonate, zinc silicate, and franklinite et al., zinc sulfide has a primary value of 49.50 percent mass fraction in the 51.16 percent total zinc. XRD was also used to analyze the component phases, and the results are shown in Figure 1, it also can be found that zinc sulfide is the dominating composition of the zinc sulfide concentrate.

Table 1. Main chemical composition of zinc sulfide concentrate (mass fraction, $\%$ ).

\begin{tabular}{cccc}
\hline $\mathbf{Z n}_{\mathbf{T}}$ & $\mathbf{S}$ & $\mathbf{F e}$ & $\mathbf{P b}$ \\
\hline 51.16 & 32.98 & 8.26 & 1.95 \\
\hline \multicolumn{4}{c}{$\mathrm{Zn}_{\mathrm{T}}$-total zinc. }
\end{tabular}

Table 2. Zinc phase distribution of zinc sulfide concentrate.

\begin{tabular}{cccccc}
\hline Zinc Phase & Zinc Sulfide & Zinc Carbonate & Zinc Silicate & Franklinite et al. & $\mathrm{Zn}_{\mathbf{T}}$ \\
\hline $\begin{array}{c}\text { Mass } \\
\text { fraction } / \%\end{array}$ & 49.55 & 0.80 & 0.64 & 0.17 & 51.16 \\
Distribution $/ \%$ & 96.85 & 1.56 & 1.25 & 0.33 & 100 \\
\hline
\end{tabular}

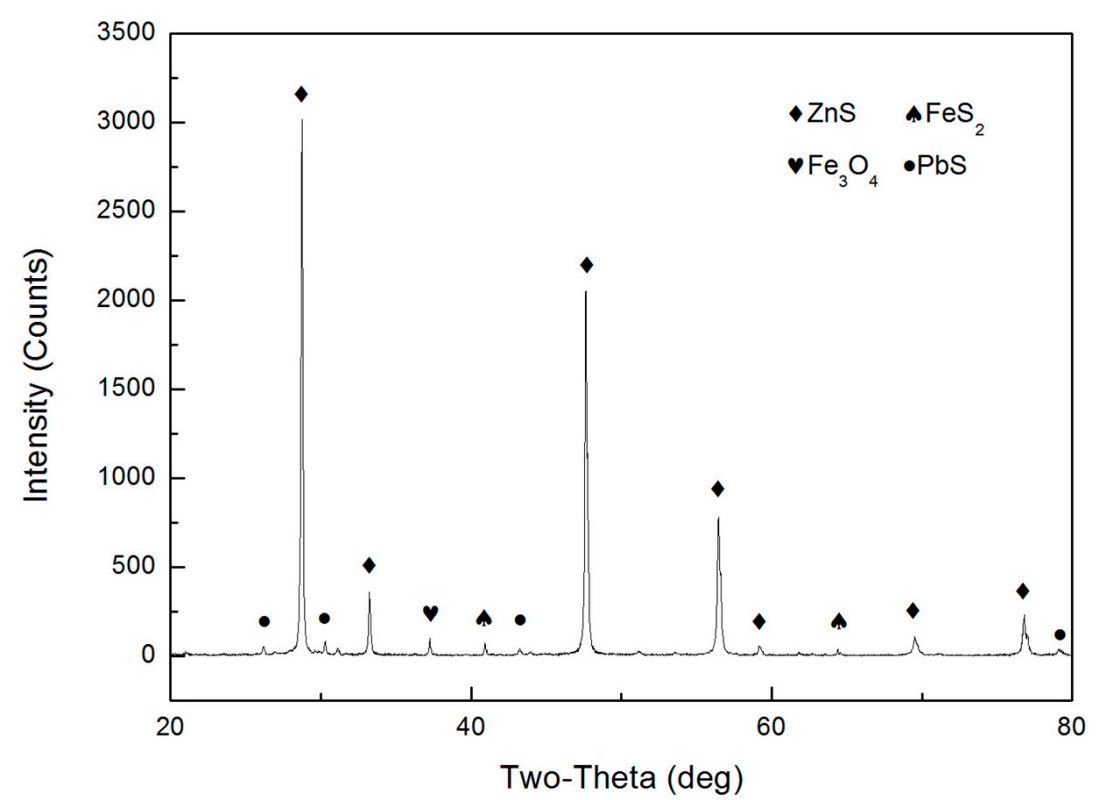

Figure 1. XRD pattern of zinc sulfide concentrate.

The zinc sulfide concentrate sample was prepared by a dry grinding and a wet grinding down to $100 \%$ passing $75 \mu \mathrm{m}$, then dried at $100{ }^{\circ} \mathrm{C}$ for $12 \mathrm{~h}$, that's because the moisture in the ore can decrease the measurement precision of dielectric properties and the drying process can remove the moisture.

\subsection{Measurement of Dielectric Properties}

Many techniques have been developed to measure the dielectric properties, for instant, transmission/reflection line, resonance cavity perturbation, free-space, and open-ended methods [12]. Each method has some advantages and disadvantages, respectively. The choice of the measurement equipment and sample holder design depend on several factors, including the operating frequency of microwave system, the dielectric materials to be characterized, extent of the research, as well as the equipment and resources that are available. For example, open-ended method may lead to lower precision since the air bubbles below the coaxial probe can result in lower values of permittivity, 
resonance cavity perturbation is typically used for low-loss materials and identifying the resonant frequency and quality factor would have been difficult due to the high absorption of the materials [13].

In this study, the resonance cavity perturbation technique was employed to measure the dielectric properties of zinc sulfide concentrate (low loss materials) during roasting at 915 and $2450 \mathrm{MHz}$ from room temperature to $850{ }^{\circ} \mathrm{C}$. The dielectric properties measure system, possessed by Key Laboratory of Unconventional Metallurgy of Ministry of Education, Kunming University of Science and Technology, is mainly comprised by four parts, $\mathrm{TM}_{0 \mathrm{n} 0}$ cavity, temperature control, Agilent N5230C vector network analyzer (Keysight Technologies, Penang, Malaysia), and computer with special dielectric properties computing software. The zinc sulfide concentrate powder was prepared in duplicate and filled in two quartz tube with inside diameter (ID) $28 \mathrm{~mm}$, outside diameter (OD) $35 \mathrm{~mm}$ and length $500 \mathrm{~mm}$. The two samples were formed by different external force, and their apparent densities were obtained by measuring their mass and volume. Measurement processes are as following: Ore sample is place in the induction furnace and heated to the designed temperature, then raised up quickly to the $\mathrm{TM}_{0 \mathrm{n} 0}$ cavity. Agilent N5230C vector network analyzer records the date changes of resonant frequency and quality factor. The testing software in the computer would calculate the parameters of dielectric properties, error date processing is considered as well. The ore sample was step-heated to $850{ }^{\circ} \mathrm{C}$ from room temperature in $50{ }^{\circ} \mathrm{C}$ steps. The two samples were measured one by one. The entire measurement process was in an air atmosphere and at atmospheric pressure.

\subsection{Thermogravimetric Analysis-Differential Scanning Calorimetry Analysis of Zinc Sulfide Concentrate}

Figure 2 represents the thermogravimetric analysis-differential scanning calorimetry (TG-DSC) curves of zinc sulfide concentrate. The zinc sulfide concentrate of $24.3100 \mathrm{mg}$ was prepared to test the TG and DSC curves under air atmosphere in $10^{\circ} \mathrm{C} / \mathrm{min}$ heating rate. It is evident that the weight of zinc sulfide concentrate decreases with the temperature increasing. The weight loss in temperature range of 400 to $500{ }^{\circ} \mathrm{C}$ is about $3 \%$ in TG curve, while that is about $14 \%$ from 620 to $850{ }^{\circ} \mathrm{C}$. It can be seen from the DSC curve that there are two peaks during temperature variation. The first peak shows that's an exothermic reaction and the peak temperature is $479^{\circ} \mathrm{C}$, the second one is an endothermic reaction and the peak temperature is $687^{\circ} \mathrm{C}$.

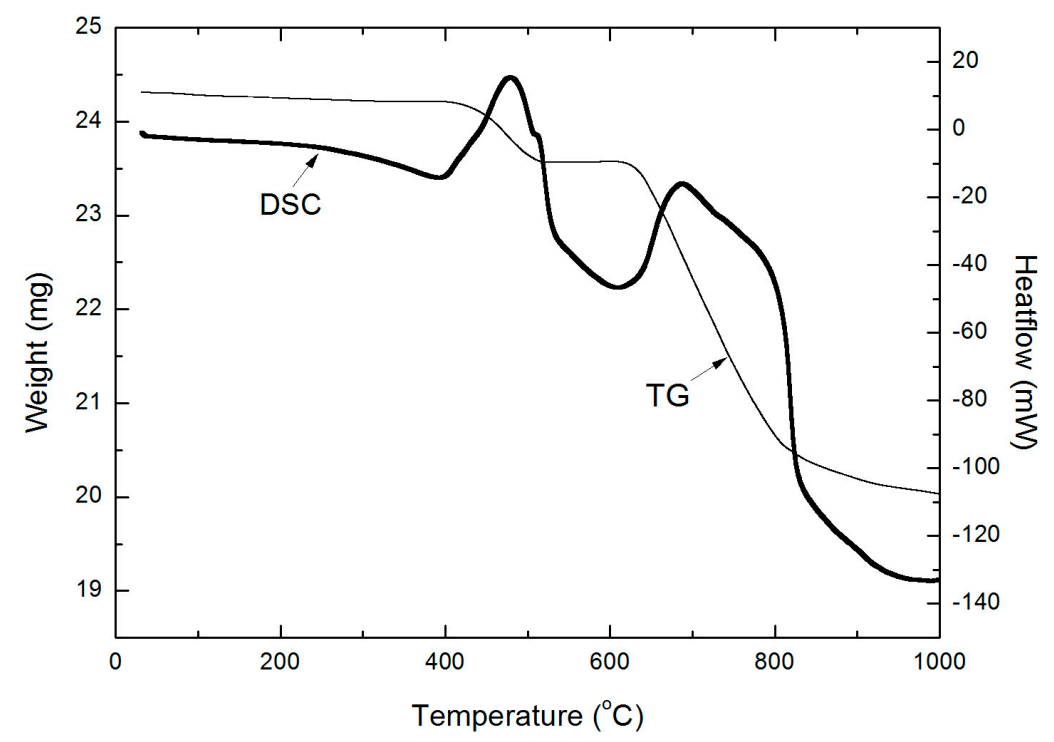

Figure 2. Thermogravimetric Analysis (TG) and differential scanning calorimetry (DSC) curves of zinc sulfide concentrate. 


\subsection{Dielectric Properties Modeling}

Regression analysis is employed to study the dielectric properties obtained from the previous study which have been fitted to two different pre-existing regression models. These models can fit the experimental curves perfectly in predicting the variations of dielectric properties. The first model is called Boltzmann model, it is based on a sigmoidal function, which can be given by $[14,15]$ :

$$
y=\frac{A_{1}-A_{2}}{1+e^{\left(T-T_{0}\right) / \mathrm{d} T}}+A_{2}
$$

where $y$ is dielectric properties (dielectric constant and dielectric loss), and temperature $T\left({ }^{\circ} \mathrm{C}\right)$ is the lone independent variable, $A_{1}, A_{2}, T_{0}$ and $\mathrm{d} T$ are the regression coefficients. The second model is Gauss model and can also be expressed as exponential form $[15,16]$ :

$$
y=y_{0}+\frac{A}{w \sqrt{\pi / 2}} e^{-\frac{2\left(T-T_{0}\right)^{2}}{w^{2}}}
$$

where $y$ is dielectric properties (dielectric constant and dielectric loss), and $T\left({ }^{\circ} \mathrm{C}\right)$ is the temperature, $w, y_{0}, T_{0}$ and $A$ are the regression coefficients.

\section{Results and Discussion}

\subsection{Dielectric Properties of Zinc Sulfide Concentrate}

The effect of the temperature on the dielectric properties of zinc sulfide concentrate for two different apparent densities 1.54 and $1.63 \mathrm{~g} / \mathrm{cm}^{3}$ at 915 and $2450 \mathrm{MHz}$ frequency is shown in Figure 3 . The dielectric constant of zinc sulfide concentrate at room temperature in this study is similar to that of previous study [2]. It can be seen from Figure 3a,c that the dielectric constant of zinc sulfide concentrate increases gradually as temperature increases from room temperature to $850{ }^{\circ} \mathrm{C}$, this could be because the energy of molecules increases with temperature increases, then the relaxation time decreases, so the response to the external electric field is faster, the dielectric constant of zinc sulfide concentrate increases immediately [17]. The dielectric constant is relatively low $(<5)$ for temperature under $450{ }^{\circ} \mathrm{C}$ because of the weak-polar nature. The dielectric constant at $2450 \mathrm{MHz}$ is mostly larger than that at $915 \mathrm{MHz}$, and the difference of the dielectric constant between 2450 and $915 \mathrm{MHz}$ is small, these experimental results are not in line with Debye equation [18], that's because of the intricate characteristics of the chemical composition and phase distribution. Similar increasing trend of dielectric constant is observed for two apparent densities and the dielectric constant of $1.63 \mathrm{~g} / \mathrm{cm}^{3}$ is always bigger than that of $1.54 \mathrm{~g} / \mathrm{cm}^{3}$. In a word, the temperature has a pivotal effect on the dielectric constant compared with frequency and apparent density.

It can be seen from Figure $3 \mathrm{~b}, \mathrm{~d}$ that the variation of dielectric loss increases gradually till $100{ }^{\circ} \mathrm{C}$ and then decreases till $200{ }^{\circ} \mathrm{C}$ for $915 \mathrm{MHz}$ and $250{ }^{\circ} \mathrm{C}$ for $2450 \mathrm{MHz}$, respectively, that's because of the release of volatile matters. Later increases sharply from 400 to about $800{ }^{\circ} \mathrm{C}$, it can be concluded that the oxidation reaction of zinc sulfide proceed gradually according to the temperature condition of zinc sulfide oxidation reaction $[19,20]$, and there is a main phase transformation in this temperature range as well, Figure 2 also can prove that there are some reactions from 400 to about $800{ }^{\circ} \mathrm{C}$. Lastly drop sharply to an almost stable value, which means main reaction have finished by compared with the dielectric properties of zinc oxide we have measured. The dielectric loss factor is the function of frequency because of dipolar rotation and ionic conduction, and ionic conduction is the dominant mechanism at lower frequencies while dipolar rotation is the main source of dielectric loss at higher microwave frequencies $[21,22]$, as shown in the following equation:

$$
\varepsilon_{\mathrm{r}}^{\prime \prime}=\varepsilon_{\mathrm{rd}}^{\prime \prime}+\varepsilon_{\mathrm{r} \sigma}^{\prime \prime}=\varepsilon_{\mathrm{rd}}^{\prime \prime}+\frac{\sigma}{2 \pi f \varepsilon_{0}}
$$


where $\varepsilon_{\text {rd }}^{\prime \prime}$ represents the loss due to dipolar rotation, and $\varepsilon_{\mathrm{r} \sigma}^{\prime \prime}$ represents the loss due to ionic conduction, and $\sigma$ is the electric conductivity $(\mathrm{S} / \mathrm{M})$.
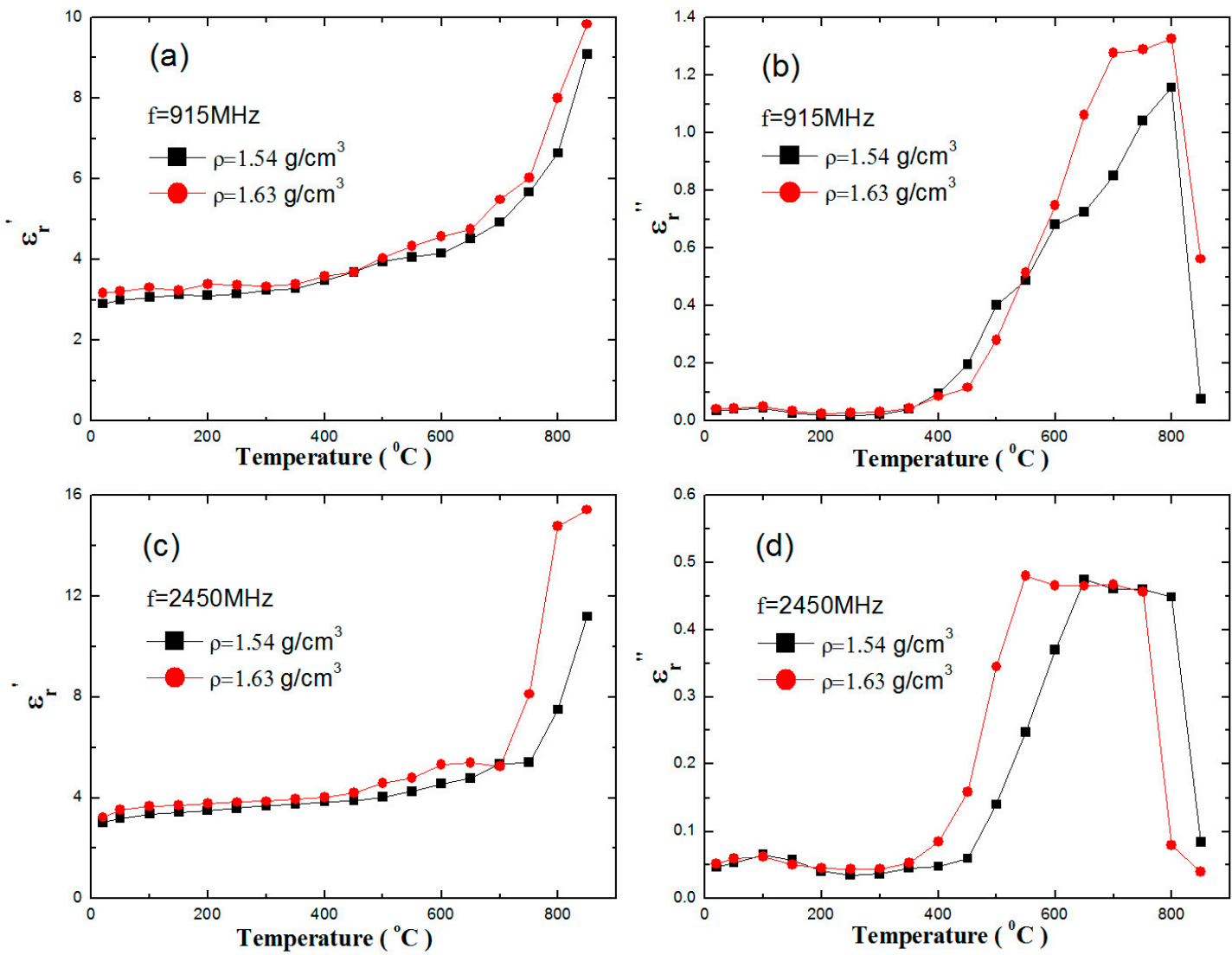

Figure 3. The variations of dielectric properties of zinc sulfide concentrate at different temperature.

The dielectric loss factor at $915 \mathrm{MHz}$ from Figure $3 \mathrm{~b}$ is smaller than that at $2450 \mathrm{MHz}$ from Figure $3 \mathrm{~d}$ when the temperature under $400{ }^{\circ} \mathrm{C}$, but reverse results when the temperature above $400{ }^{\circ} \mathrm{C}$. It can be concluded that dipolar rotation is the main contribution to the loss factor when temperature under $400{ }^{\circ} \mathrm{C}$, while ionic conduction contributes mainly to the loss factor when temperature above $400{ }^{\circ} \mathrm{C}$ because thermal agitation disturbs the alignment of the molecule dipole with the electric field and conduction increases as the temperature increases, similar results have also been reported by some literature [22,23]. In addition, the dielectric loss factor of apparent density of $1.63 \mathrm{~g} / \mathrm{cm}^{3}$ is mostly larger than that of $1.54 \mathrm{~g} / \mathrm{cm}^{3}$ for the same temperature. Hence, the temperature, frequency and apparent density have a great effect on the dielectric loss factor.

Figure 4 shows the temperature dependence of dielectric loss tangent at 915 and $2450 \mathrm{MHz}$ for two different apparent densities 1.54 and $1.63 \mathrm{~g} / \mathrm{cm}^{3}$. Properly speaking, the materials that can be heated well in an electric field have high values of $\tan \delta$, and materials that can be heated poorly have low values of $\tan \delta$, based on this feature, they are often referred to as "high loss" or "low loss" materials, respectively. It can be seen from Figure 4 that the zinc sulfide concentrate is medium loss material when the temperature less than about $450{ }^{\circ} \mathrm{C}$, and zinc sulfide concentrate is high loss material because of $\tan \delta>3 \times 10^{-2}$ when the temperature change approximately from 450 to $800^{\circ} \mathrm{C}$. The loss tangent at $915 \mathrm{MHz}$ is larger than that at $2450 \mathrm{MHz}$ for temperature above $400{ }^{\circ} \mathrm{C}$, the maximum values of loss tangent are 0.232 at $2450 \mathrm{MHz}$ and 0.100 at $2450 \mathrm{MHz}$, respectively. The zinc sulfide concentrate of bigger apparent density for a given temperature mostly has a higher value of dielectric loss factor, it can be concluded that the loss tangent increases and reaction process accelerates as the apparent 
density increases suitably, similar results for room temperature can be found in literature [24,25], so we can enhance the ability of absorbing microwave by increasing the apparent density.
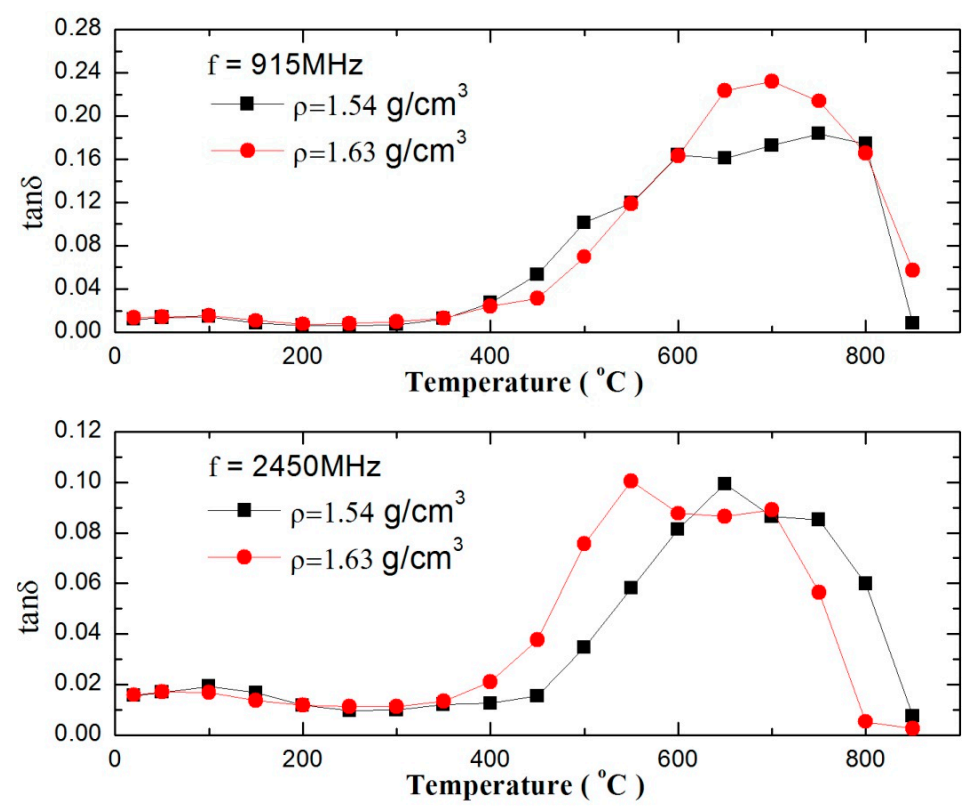

Figure 4. The variations of dielectric loss tangent of zinc sulfide concentrate with temperature.

\subsection{Effect of Temperature on Penetrate Depth of Zinc Sulfide Concentrate}

Figure 5 presents the temperature dependence of penetration depth at 915 and $2450 \mathrm{MHz}$ for two different apparent densities- 1.54 and $1.63 \mathrm{~g} / \mathrm{cm}^{3}$. It can be found that the variation tendency of the penetration depth is same for four curves. The frequency and temperature have a more great effect on the penetrate depth rather than the apparent density. It can be concluded that zinc sulfide concentrate can be heated well from 450 to $800{ }^{\circ} \mathrm{C}$, and $2450 \mathrm{MHz}$ is beneficial to the efficient heat while $915 \mathrm{MHz}$ is in favor of uniform heating.
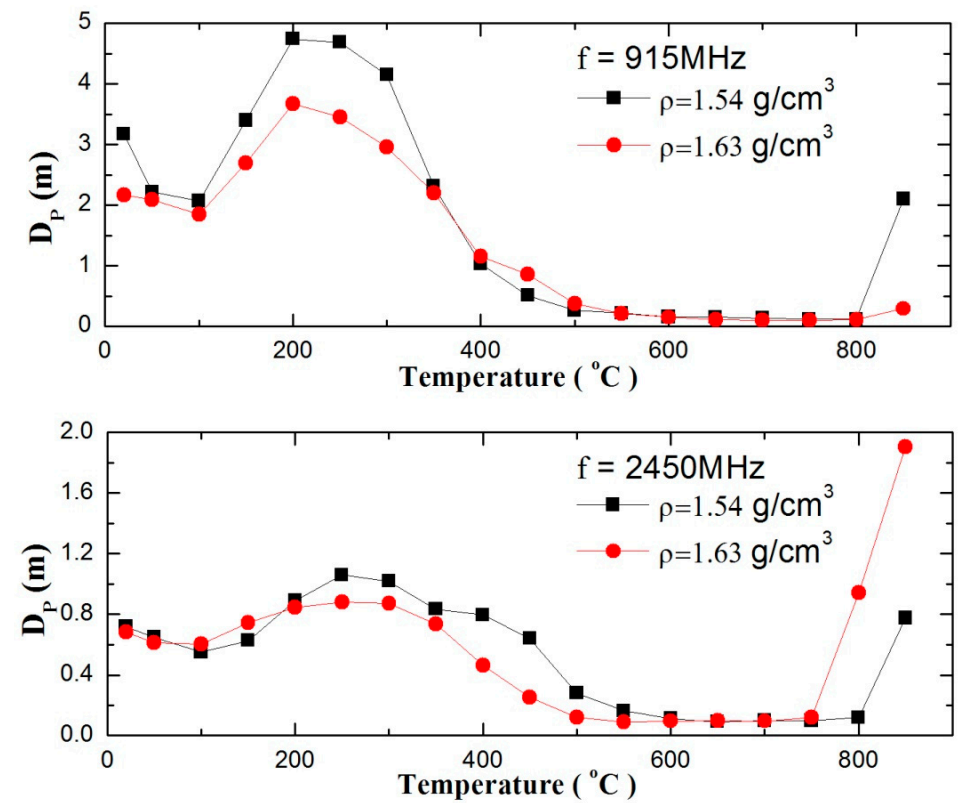

Figure 5. The variations of penetration depth of zinc sulfide concentrate with temperature. 


\subsection{Heating Experimental Results in the Microwave Oven}

Filled in an alumina crucible, $30 \mathrm{~g}$ zinc sulfide concentrate with the apparent density of $1.63 \mathrm{~g} / \mathrm{cm}^{3}$ was heated by $2450 \mathrm{MHz}$ microwave oven at power of $1000 \mathrm{~W}$. The method of microwave auxiliary heating by using silicon carbide was employed from room temperature to $450{ }^{\circ} \mathrm{C}$, then silicon carbide was taken out quickly from the microwave cavity, later the zinc sulfide concentrate was heated directly by microwave energy. Heating experimental results show that it needs 26 min from 450 to $800{ }^{\circ} \mathrm{C}$, heating rate is $13.85^{\circ} \mathrm{C} / \mathrm{min}$.

\subsection{Modeling the Dielectric Constant}

The experimental values of dielectric properties of zinc sulfide concentrate were fitted to two pre-existing regression models viz. Boltzmann and Gauss regression model. It can be found that the Boltzmann model is suited to fit the dielectric constant of zinc sulfide concentrate and Gauss model is suited to fit the dielectric loss. Figure 6 shows the Boltzmann fitting of dielectric constant and Gauss fitting of dielectric loss for apparent density $1.63 \mathrm{~g} / \mathrm{cm}^{3}$ at 915 and $2450 \mathrm{MHz}$. The fitting results of regression coefficient and coefficient of determination $\left(R^{2}\right)$ are summarized in Table 3. It can be seen that the $R^{2}$ value of Boltzmann fit is 0.99 for $915 \mathrm{MHz}$ and 0.97 for $2450 \mathrm{MHz}$ compared to 0.97 for $915 \mathrm{MHz}$ and 0.90 for $2450 \mathrm{MHz}$ of Gauss fit. Since $R^{2}$ indicates how well the function is fitted to the experimental values, very high values of $R^{2}(>0.9)$ in two models implies that predicted value of zinc sulfide concentrate dielectric properties is very close to the experiment results. The predicted values of zinc sulfide concentrate dielectric properties will be helpful to design and simulate large size microwave system.
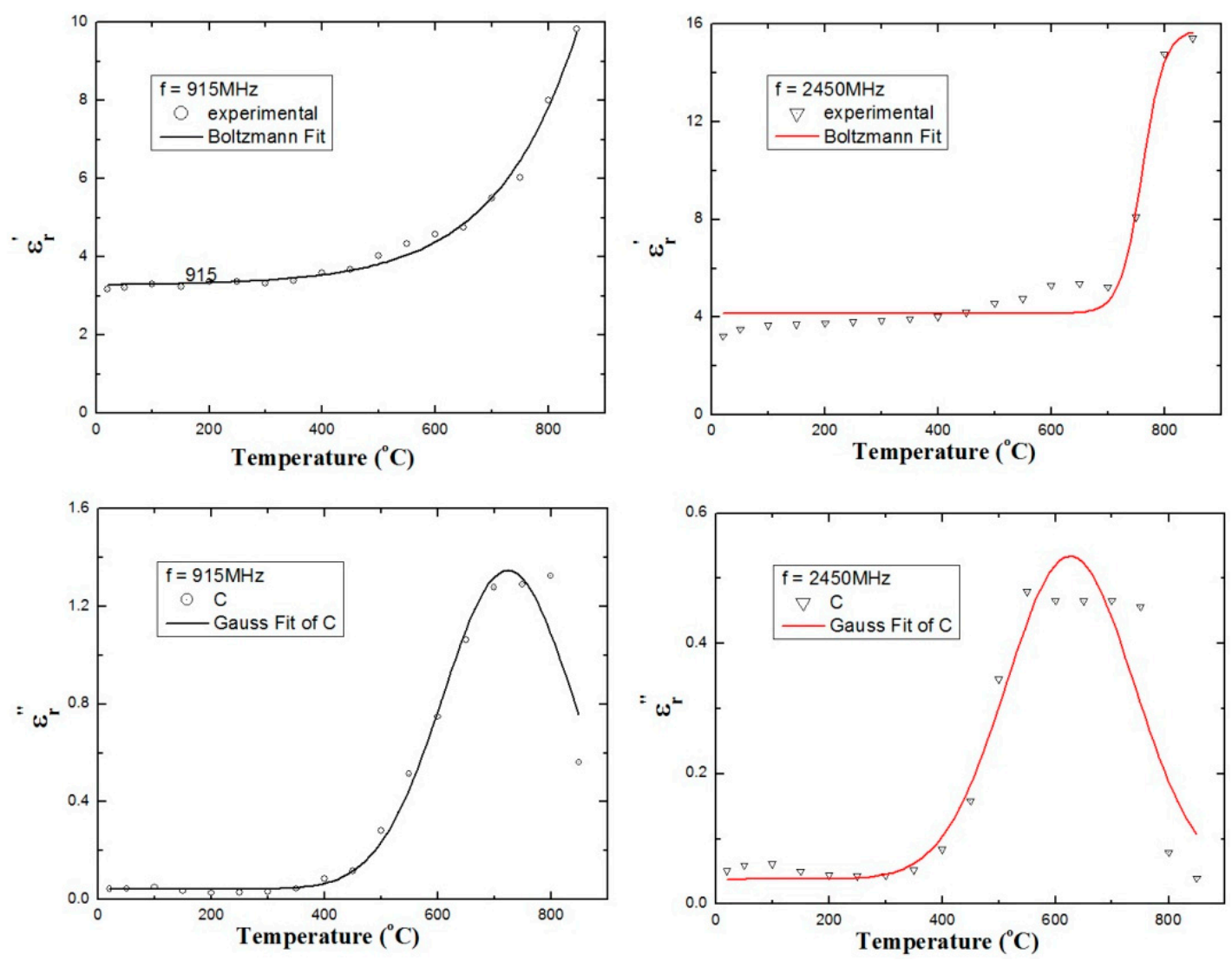

Figure 6. Experimental values of dielectric properties fitted with Boltzmann model and Gauss model for apparent density $1.63 \mathrm{~g} / \mathrm{cm}^{3}$ at $915 \mathrm{MHz}$ and $2450 \mathrm{MHz}$. 
Table 3. Regression coefficients and $R^{2}$ values for Boltzmann model and Gauss model fitted to the dielectric properties experimental results.

\begin{tabular}{cccccccc}
\hline Parameter & Model & Frequency & \multicolumn{4}{c}{ Regression Coefficients } & $\boldsymbol{R}^{\mathbf{2}}$ \\
\hline \multirow{2}{*}{$\varepsilon_{\mathrm{r}}^{\prime}$} & Boltzmann & $915 \mathrm{MHz}$ & $A_{1}$ & $A_{2}$ & $T_{0}$ & $\mathrm{~d} T$ & \\
& model & $2450 \mathrm{MHz}$ & 4.16 & $46,800.40$ & 2108.67 & 141.71 & 0.99 \\
& & & $y_{0}$ & $T_{0}$ & $w$ & $A$ & \\
$\varepsilon_{\mathrm{r}}^{\prime \prime}$ & Gauss & $915 \mathrm{MHz}$ & 0.04 & 724.12 & 228.83 & 374.52 & 0.97 \\
& model & $2450 \mathrm{MHz}$ & 0.04 & 626.37 & 225.13 & 139.98 & 0.90 \\
\hline
\end{tabular}

\section{Conclusions}

The dielectric properties of zinc sulfide concentrate were determined by using resonance cavity perturbation technique, how temperature, frequency and apparent density effect on the dielectric properties have been studied numerically. The dielectric constant increases gradually with temperature and apparent density increases, decreases mostly with the frequency increases, the temperature has a key role to the dielectric constant. All of temperature, apparent density and frequency have a significant impact to the dielectric loss factor. It can be concluded by the loss tangent and penetration depth that the zinc sulfide concentrate is high loss material from 450 to $800^{\circ} \mathrm{C}$, its ability of absorbing microwave energy would be enhanced by increasing the apparent density. The experimental results also have proved that the zinc sulfide concentrate is high loss material from 450 to $800^{\circ} \mathrm{C}$. The dielectric constant and loss factor can be fitted perfectly by Boltzmann model and Gauss model, respectively.

Acknowledgments: This work was supported by National Program on Key Basic Research Project of China (973 Program, 2014CB643404), National Natural Science Foundation of China (51604135), National Natural Science Foundation of China (No. 51564033), Key Project of Applied Basic Research of Yunnan Province (No. 2016FA023).

Author Contributions: Guangjun He conceived and designed the experiments, analyzed the data and wrote the paper under the supervision and guidance of Libo Zhang and Jinhui Peng; Shiwei Li gave many useful suggestions and revised the grammar of the manuscript. Jian Liu and Peng Liu performed the experiments; Kun Yang contributed ore grinding and analysis of chemical composition and zinc phase distribution.

Conflicts of Interest: The authors declare no conflict of interest.

\section{References}

1. Gregurek, D.; Peng, Z.W.; Wenzl, C. Lead and zinc metallurgy. JOM 2015, 67, 1986-1987. [CrossRef]

2. Al-harahsheh, M.; Kingman, S.; Bradshaw, S. The reality of non-thermal effects in microwave assisted leaching systems? Hydrometallurgy 2006, 84, 1-13. [CrossRef]

3. Thostenson, E.T.; Chou, T.W. Microwave processing: Fundamentals and applications. Compos. Part A Appl. Sci. Manuf. 1999, 30, 1055-1071. [CrossRef]

4. Haque, K.E. Microwave energy for mineral treatment process-A brief review. Int. J. Miner. Process. 1999, 57, 1-24. [CrossRef]

5. Tang, J.M. Unlocking potentials of microwaves for food safety and quality. J. Food Sci. 2015, 80, 1776-1793. [CrossRef] [PubMed]

6. Peng, Z.W.; Hwang, J.Y.; Kim, B.G.; Mouris, J.; Hutcheon, R. Microwave absorption capability of high volatile bituminous coal during pyrolysis. Energy Fuels 2012, 26, 5146-5151. [CrossRef]

7. Laybourn, A.; Katrib, J.; Palade, P.A.; Easun, T.L.; Champness, N.R.; Schroder, M.; Kingman, S.W. Understanding the electromagnetic interaction of metal organic framework reactants in aqueous solution at microwave frequencies. Phys. Chem. Chem. Phys. 2016, 18, 5419-5431. [CrossRef] [PubMed]

8. Tripathi, M.; Sahu, J.N.; Ganesan, P.; Dey, T.K. Effect of temperature on dielectric properties and penetration depth of oil palm shell (OPS) and OPS char synthesized by microwave pyrolysis of OPS. Fuel 2015, 153, 257-266. [CrossRef]

9. Beatriz, G.B.; Jose, C.C.; Felipe, P.F.; Pedro, P.G.; Gabriel, L.V. In situ monitoring of materials at high temperatures through dielectric properties measurement. Materials 2016, 9, 349. 
10. Chen, W.H.; Zhang, L.B.; Peng, J.H.; Yin, S.H.; Ma, A.Y.; Yang, K.; Li, S.W.; Xie, F. Effects of roasting pretreatment on zinc leaching from complicated zinc ores. Green Process. Synth. 2016, 5, 41-47. [CrossRef]

11. Yang, K.; Li, S.W.; Zhang, L.B.; Peng, J.H.; Chen, W.H.; Xie, F.; Ma, A.Y. Microwave roasting and leaching of an oxide-sulfide zinc ore. Hydrometallurgy 2016, 166, 243-251. [CrossRef]

12. Makul, N.; Rattanadecho, P.; Agrawal, D.K. Applications of microwave energy in cement and concrete-A review. Renew. Sustain. Energy Rev. 2014, 37, 715-733. [CrossRef]

13. Beberoso, D.; Albero-ortiz, A.; Monzo-cabrera, J.; Diza-morcillo, A.; Arenills, A.; Menendez, J.A. Dielectric characterization of biodegradable wastes during pyrolysis. Fuel 2016, 172, 146-152. [CrossRef]

14. Motasemi, F.; Afzal, M.T.; Salema, A.A.; Mouris, J.; Hutcheon, R.M. Microwave dielectric characterization of switchgrass for bioenergy and biofuel. Fuel 2014, 124, 151-157. [CrossRef]

15. Motasemi, F.; Afzal, M.T.; Salema, A.A. Microwave dielectric characterization of hay during pyrolysis. Ind. Crop. Prod. 2014, 61, 492-498. [CrossRef]

16. Sun, J.; Wang, W.L.; Yue, Q.Y. Review on microwave-matter interaction fundaments and efficient microwave-associated heating strategies. Materials 2016, 9, 231. [CrossRef]

17. Muley, P.D.; Boldor, D. Investigation of microwave dielectric properties of biodiesel components. Bioresour. Technol. 2013, 127, 165-174. [CrossRef] [PubMed]

18. Julrat, S.; Chongcheawchamnan, M.; Robertson, L.D. Characterization of the dielectric properties of rubber latex from 0.5 to $33 \mathrm{GHz}$. Biosyst. Eng. 2014, 125, 1-8. [CrossRef]

19. Zhang, Y.L.; Yu, X.J.; Li, X.B. Zinc recovery from franklinite by sulphation roasting. Hydrometallurgy 2011, 109, 211-214. [CrossRef]

20. Boyanov, B.; Peltekov, A.; Petkova, V. Thermal behavior of zinc sulfide concentrates with different iron content at oxidative roasting. Thermochim. Acta 2014, 586, 9-16. [CrossRef]

21. Peng, Z.W.; Hwang, J.Y. Microwave-assisted metallurgy. Int. Mater. Rev. 2015, 60, 30-63. [CrossRef]

22. Franco, A.P.; Yamamoto, L.Y.; Tadini, C.C.; Gut, J.A. Dielectric properties of green coconut water relevant to microwave processing: Effect of temperature and field frequency. J. Food Eng. 2015, 155, 69-78. [CrossRef]

23. Peng, Z.W.; Lin, X.L.; Wu, X.J.; Hwang, J.Y.; Kim, B.G.; Zhang, Y.B. Microwave absorption characteristics of anthracite during pyrolysis. Fuel Process. Technol. 2016, 150, 58-63. [CrossRef]

24. Nowak, D.; Granat, K.; Opyd, B. Examination and analysis of influence of compaction degree on dielectric properties of moulding sand components. Metalurgija 2015, 54, 353-356.

25. Zhang, L.B.; Ma, A.Y.; Liu, C.H.; Qu, W.W.; Peng, J.H.; Luo, Y.G.; Zuo, Y.G. Dielectric properties and temperature increase characteristics of zinc oxide dust from fuming furnace. Trans. Nonferr. Met. Soc. China 2014, 24, 4004-4011. [CrossRef]

(C) 2017 by the authors. Licensee MDPI, Basel, Switzerland. This article is an open access article distributed under the terms and conditions of the Creative Commons Attribution (CC BY) license (http:/ / creativecommons.org/licenses/by/4.0/). 